\title{
TRABALHO, PRECARIZAÇÃO E DOR: O QUE PENSAM OS TRABALHADORES DA CONSTRUÇÃ̃O CIVIL? ${ }^{1}$
}

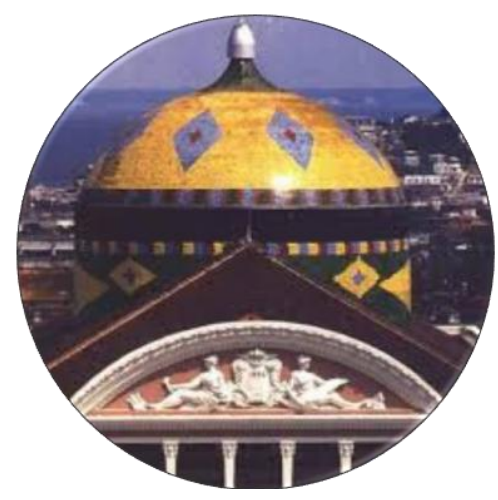

Érika L. Almeida Soares ${ }^{2}$

\section{Resumo}

Analisar as relações entre o trabalho e o processo saúde-doença de trabalhadores do setor da construção civil, na cidade de Manaus-AM, constituiu o cerne deste estudo. Adotou-se como fonte de pesquisa documental, os relatos de experiências de adoecimentos de 44 (quarenta e quatro) trabalhadores do setor da construção civil, atendidos no Centro de Referência em Saúde do Trabalhador-CEREST/ SEMSA, no período de 2005 a 2010. Buscando realçar a dimensão social do processo de adoecimento relacionado ao trabalho, num contexto de (re) organização do trabalho, a pesquisa identificou algumas das situações desencadeadoras dos agravos que afetam a saúde dos trabalhadores, assim como analisou as experiências de dor e sofrimento pelas quais vivenciam os trabalhadores da construção civil na contemporaneidade.

Palavras-chave: Trabalho. Saúde-doença. Trabalhadores. Construção Civil.

\begin{abstract}
Analyzing the relationships between work and the health-disease process of construction workers in the city of Manaus-AM, was the core of this study. It was adopted as a source of documentary research, the reports of experiences of sickness of 44 (forty-four) workers in the civil construction sector, attended at the Reference Center on Occupational HealthCEREST / SEMSA, from 2005 to 2010. In order to highlight the social dimension of the
\end{abstract}

$1 \mathrm{O}$ presente artigo foi elaborado, num primeiro momento, com base em pesquisa realizada para a elaboração de monografia referente à conclusão do curso de Especialização Saúde do Trabalhador e Meio Ambiente STMA), no ano de 2011, organizado pela Universidade do Estado do Amazonas (UEA) e financiado pela Secretaria de Saúde do Estado do Amazonas (SUSAM).

2 Mestre em Sociedade e Cultura na Amazônia pelo PPGSCA/ UFAM e Socióloga no Centro de Referência de Saúde do Trabalhador (CEREST/ SEMSA). E-mail: erika1857@bol.com.br 
work-related illness, in a context of (re) organization of work, the research identified some of the situations that trigger the health effects of workers, as well as analyzed the experiences of pain and suffering for which experience the construction workers in contemporary times.

Keywords: Job. Health-disease. Workers. Construction

\section{Trabalho, reestruturação produtiva e saúde: a construção civil em questão}

Em um contexto de reestruturação produtiva do capital ${ }^{\mathrm{i}}$, o modelo flexível, que incide da gestão à organização da produção, repercute por toda a morfologia do trabalho (Antunes, 2001 e 2004). Considerando as diferentes configurações que o trabalho pode assumir, essas transformações afetam tanto a forma de organização da força de trabalho quanto o processo de trabalho dos diferentes setores da economia - da indústria ao setor de serviços.

Em se tratando do setor da construção civil, pode-se dizer que há uma espécie de amálgama de modelos de organização de produção e do trabalho. O novo e o velho coexistem. Por isso, contrariando visões conservadoras, a construção civil não condiz com um setor econômico que se organiza somente em bases e princípios tradicionais quanto ao processo de produção. Ao contrário, este setor sempre experimentou "métodos e técnicas de racionalização dos processos de trabalho ao longo dos anos" (Villela, 2007, p. 11).

Dito de outro modo, o processo de reestruturação produtiva na indústria da construção civil evidencia que a velocidade e o ritmo das mudanças ocorrem, mas de modo particular. Por isso, dependendo do país, região ou da empresa, é possível que a incorporação de novos métodos de construção e de tecnologias inovadoras, assim como as modernas formas de organização da força de trabalho, ocorra em momentos e modos distintos. Em relação à indústria da construção civil, pode-se dizer que há algumas tendências que vêm marcando a (re) organização do processo de produção e de trabalho, tais como: a) no lugar da 
inserção de máquinas modernas, verifica-se o uso ampliado de novos produtos e materiaisii; b) a expansão do sistema de montagem em detrimento do sistema de construção no processo de trabalho; e c) a manutenção de materiais e sistemas construtivos tradicionais.

Enquanto que o moderno, representado pelas inovações técnicas e tecnológicas, em especial nos materiais e produtos, ganha força e se reproduz de forma acelerada num contexto de permanente (re) organização do trabalho dos canteiros de obras, onde convive e se mescla com o tradicional, ou seja, com o trabalho degradante, desprotegido, enfim, precarizado. Porém, esta não é uma face recente do trabalho na construção civil. Ao contrário, é nítida a permanência de vários processos de trabalho considerados arcaicos, obsoletos ou antiquados, mesmo com o avanço de novos modos de organizar a produção e o trabalho no setor (Soares apud Villela, 2008).

Pode-se afirmar, então, que no capitalismo contemporâneo, continua a ocorrer um desperdício da vida e, consequentemente, da saúde do trabalhador, como precisava Karl Marx, ao analisar os primórdios do capitalismo moderno. Assim, ao considerarmos o trabalho como mediador orgânico entre o homem e a natureza, que é marcado pela alienação e estranhamento (Marx, 2004), qualquer tentativa de explicação acerca dos processos dos agravos que afetam a saúde dos trabalhadores, deve considerar as contradições históricas da relação entre capital e trabalho.

Diante disso, acidentes e doenças relacionadas ao trabalho não devem ser vistos como mero "infortúnio, infelicidade ou má sorte" (Lacaz apud Lourenço e Bertani, 2007) ou de responsabilização individual do trabalhador, que comete "atos inseguros" (Santana e Oliveira, 2004) em caso de acidente. Deve-se, sim, considerar aspectos centrais para a explicação dessas situações, como a organização e a gestão do processo de trabalho e da produção.

No entanto, a ocorrência dos agravos que afetam à saúde do trabalhador da construção civil, sejam os relacionados aos acidentes de trabalho, sejam os oriundos de doenças agravadas ou decorrentes do trabalho, não se trata de um fenômeno social recente. Ao contrário, historicamente, esse grupo de trabalhadores tem convivido com condições de trabalho insalubres e situações de precarização nas relações de trabalho. 
Nesse sentido, as condições de trabalho, aliadas aos aspectos sociais e ambientais, condicionam e/ ou determinam a situação de saúde de uma dada categoria profissional e contribuem para a definição de um perfil epidemiológico. No âmbito da construção civil, alguns estudos indicam que os trabalhadores realizam, em muitos casos, sua atividade laboral em ambiente insalubre e de modo arriscado (Silveira et.al., 2005). Segundo Santana e Oliveira (2004, p. 797.), os sintomas relacionados à dimensão músculo-esquelética, às dermatites, às intoxicações por chumbo e à exposição a asbestos, predominam na lista de enfermidades de risco que afetam o trabalhador da construção civil.

O atual panorama do mundo do trabalho tem aprofundado, em certos casos, antigos problemas de saúde e segurança no trabalho (Gomes e Costa, 2003) e, em outros, contribuído com traços novos no processo de adoecimento dos trabalhadores. Quanto aos acidentes, o trabalho na construção civil representa insegurança e risco permanente para o conjunto de trabalhadores do setor. Esse quadro vem se agravando desde o início dos anos noventa, no Brasil, apesar da criação do Sistema Único de Saúde iii (SUS) e, posteriormente, da implantação de uma Política Nacional de Saúde do Trabalhadoriv.

Salerno apud Santana et. al., 2004, afirma que a construção civil, no Brasil, é uma das atividades econômicas de maior risco de acidentes fatais e de não-fatais. Entre 2004 e 2006, no Brasil, o setor da construção civil apresentou 28.875 e 31.529 , respectivamente (INSS, 2007), em acidentes de trabalho.

No período entre os anos de 2005 e 2010, no Estado do Amazonas, pôde-se constatar um aumento significativo do número de acidentes de trabalhov na construção civil. Só para ilustrar, em 2005, o número total de trabalhadores acidentados foi de 271 (duzentos e setenta e um) casos. Já, em 2010, o número absoluto chegou a 876 (oitocentos e setenta e seis). Entretanto, é importante destacar também que houve nesse período variação do número de empregos formais neste setor da economia. Conforme dados do DIEESE (2010), o recente cenário de emprego e trabalho do Estado do Amazonas aponta que, no ano de 2007, havia um estoque de 21.667 empregos formais; em 2008, era de 25.373; e, em 2009, de 25.450. Esses dados mostram que não há uma variação significativa do número de empregos formais. Em contrapartida, houve um aumento significativo do número de acidentes e doenças do trabalho na construção civil. 
É importante notar que os dados acima citados correspondem apenas aos trabalhadores formais. Encontram-se excluídos dessas notificações oficiais os trabalhadores que atuam em condições de maior vulnerabilidade social, isto é, os milhares de trabalhadores que desenvolvem atividades de empreiteiro, diarista e avulso, só para citar algumas modalidades, a serviço das empresas denominadas de terceirizadas ou quarterizadas no setor da construção civil.

Outras fontes oficiais, como as publicizadas pelo Ministério do Trabalho e Emprego, no Estado do Amazonas, informam que o número de autos de

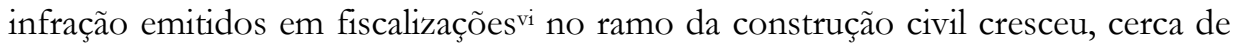
113\%, entre os anos de 2008 e 2010, em comparação com o período de 2005 a 2007. A construção civil é o setor que representa de $15,31 \%$ de todas as ações fiscais de segurança e saúde no trabalho do Estado.

O Ministério Público do Trabalho (MPT), no Amazonas, por sua vez,

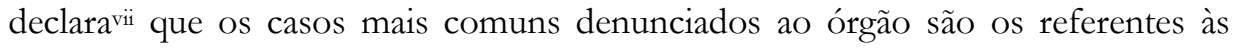
doenças ocupacionais e a falta de segurança e qualidade de vida no ambiente de trabalho. Entre os trabalhadores que mais denunciam, segundo o MPT/ AM, estão os da indústria (PIM) e os da construção civil. Segundo a Previdência Social, no comparativo do período de janeiro e junho, entre 2008 e 2009, houve um aumento de 7,6\% em relação ao número de auxílios doença do Estado do Amazonas. Nesse quadro, entre os trabalhadores da construção civil os problemas de saúde/ doença são ocasionados principalmente pelas quedas e fraturas em ambiente de trabalhoviii.

Se o processo de reestruturação produtiva desenvolve-se na construção civil com algumas características singulares, os seus efeitos no quadro de agravos à saúde do trabalhador, também se constitui com a presença de elementos particulares. Não obstante, ainda é possível a identificação de agravos tradicionalmente sofridos por estes trabalhadores, como é o caso daqueles decorrentes de acidentes, com destaque para os ocasionados por quedas. Já os agravos relacionados às doenças ocupacionais destacam-se as de origem músculoesquelética.

Pode-se afirmar, então, que "as condições de saúde e segurança também não têm apresentado grandes avanços, e ainda há uma alta ocorrência de acidentes de trabalho no setor e os trabalhadores são 
submetidos, muitas vezes, a condições muito precárias" (DIEESE, 2010, p. 22). $\mathrm{Na}$ verdade, em certas situações parece que há regressões ${ }^{\mathrm{ix}}$. Contraditoriamente,

enquanto os projetos, a especificação de materiais e as técnicas construtivas tendem a se sofisticar dia-a-dia, a execução, as ferramentas e as condições de trabalho nos canteiros de obras permanecem, em muitos casos, rudimentares, sendo empregados métodos e formas de trabalho improvisadas (Franco apud Villela, 2007).

Assim, as pretéritas situações de riscos graves à vida e à saúde do trabalhador permanecem, mesmo que amalgamadas à inserção de técnicas e tecnologias modernas.

\section{O trabalho na construção civil: entre a precarização e a dor}

No período entre os anos de 2005 a 2010, o CEREST/ SEMSA atendeu 44 (quarenta e quatro) trabalhadores oriundos do setor da construção civil ${ }^{\mathrm{x}}$, sendo 41 (quarenta e um) homens e 03 (três) mulheres. A idade média de idade desses trabalhadores pode ser considerada alta, já que quarenta deles têm acima de 30 anos de idade.

Quanto ao nível de escolaridade, registrou-se um baixo número de anos de estudos formais desses trabalhadores, já que, pelo menos, trinta e seis desses trabalhadores se quer concluiu o ensino fundamental, enquanto que somente dois deles possuem o ensino médio completo. A maioria, cerca de 23 (vinte e três) deles, é oriunda do Estado do Amazonas, principalmente de municípios do interior.

A ocupação de pedreiro foi a mais referenciada, precisamente 17 (dezessete) vezes, e, em segundo lugar, a de servente/ ajudante, com 07 (sete) trabalhadores. Ao serem perguntados sobre o tempo de trabalho na indústria da construção civil, 24 (vinte e quatro) deles informou que está há 
mais de cinco anos e somente 09 (nove) com menos dois anos. Em relação à renda mensal, 35 (trinta e cinco) desses trabalhadores informou que recebe até dois salários mínimos mensalmente, enquanto cinco trabalhadores recebem acima de três salários mínimos. Esse dado, de certo modo, ratifica que historicamente os trabalhadores da construção civil ainda obtêm rendimentos baixos no contexto da massa assalariados dos ocupados no país ${ }^{\mathrm{xi}}$.

Sobre a questão da origem social desses trabalhadores e sua relação com os rendimentos salariais no setor da construção civil, Ponchmann et. al. (2007, p. 42), analisa que, entre os anos de 1960 e 1980, a recomposição do mercado de trabalho urbano contou com o ingresso de milhões de imigrantes rurais. Em sua maioria, este contingente de trabalhadores tinha baixa escolaridade e qualificação profissional. Uma parte significativa desses trabalhadores terminou por massificar as ocupações de serviços pessoais e na construção civil, em especial ocupando as vagas de encanador, eletricista, pintor, servente, pedreiro, chaveiro, vigia, entre outras.

Disso depreende-se que a dinâmica das ocupações de trabalho no setor da construção civil historicamente tem contato com farta mão-deobra disponível num contexto desigual de mercado geral de trabalho, como é o caso brasileiro. $\mathrm{Na}$ verdade, o trabalhador da construção civil, ainda hoje, pode ser identificado com o perfil apresentado em décadas pretéritas, ou seja, como do sexo masculino, com média de idade superior aos demais setores da economia, com baixa escolarização e, em geral, é migrante (DIEESE, 2001).

\section{Dor e penosidade no trabalho: os relatos dos trabalhadores}

Entre as queixas referenciadas pelo trabalhador da construção civil, a dor na coluna (dorsal, cervical ou lombar) foi a mais freqüente. Este 
tipo de queixa reforça o fenômeno de alta incidência de agravos à saúde do trabalhador que afetam o seu sistema músculo-esquelético (Santana e Oliveira, 2004, p. 797). Em seguida, as queixas referentes à dor no joelho e nos membros superiores, como mãos, punhos, ombros e braços foram as mais informadas pelos trabalhadores.

Nesse sentido, as dificuldades para movimentar membros superiores e/ ou inferiores e a diminuição de movimentos da coluna, de modo geral, impõem novos limites aos seus corpos. Situação esta agravada quando da convivência permanente com a dor, principalmente em casos que o trabalhador tem que permanecer no desempenho de suas funções no trabalho ou quando há dificuldades em ter acesso ao tratamento no Sistema Único de Saúde.

Por certo, a vida e a saúde (e, por conseqüência, o corpo) do trabalhador sofrem um intenso processo de desgaste no capitalismo. Se anteriormente o capital utilizava como meio de extração de mais-valia as extenuantes jornadas de trabalho, hoje, a penosidade do/ no trabalho se dá também pela intensidade do processo de trabalho (Linhart, 2011, p. 149). Essa intensidade pode acarretar níveis alarmantes de desgaste no corpo do trabalhador. Com efeito, o trabalhador da construção civil, ao lidar com tarefas que exigem carregar pesos acima do que o corpo suporta, sob um ritmo de produção intenso e de uma jornada diária extensa, traz consigo o estigma da precariedade e da penosidade do/ no trabalho.

Ao serem perguntados sobre a situação de acidente ou o momento que teria desencadeado algum desconforto ou dor, as situações mais citadas pelos trabalhadores são as seguintes:

Os casos de (1) acidentes decorrentes de quedas representam o tipo de acidente mais freqüente de acordo com os relatos dos trabalhadores consultados. Em algumas situações, o acidente é potencializado por conta de limites impostos ao corpo adquiridos em trabalhos anteriores. Como o acidente descrito, a seguir: “O trabalhador estava passando do alçapão para 
a laje da caixa d'água quando apôiou-se na parede e quebrou a massa. $\mathrm{O}$ mesmo escorregou a mão (sic) topando o dedo na laje”. O trabalhador já tinha uma lesão no dedo decorrente de um acidente anterior, em 2003, e, desde então, não tem movimento no dedo indicador da mão direita, dificultando, assim a sua destreza no desenvolvimento de suas tarefas. Este caso ressalta que o trabalhador, em inúmeras ocasiões, traz a marca da violência que o trabalho pode ocasionar no seu próprio corpo ${ }^{\mathrm{xii}}$.

Sobre as formas que a empresa administra casos de trabalhador acidentado, um dos relatos chama a atenção: “após acidente, decorrente de queda de uma altura de aproximadamente seis metros, foi relotado como vigia noturno, já que sente forte dor lombar”. Apesar do médico da empresa ter avaliado que ele não tem doença alguma ou limitação para voltar a realizar a sua função anterior, a de ajudante de pedreiro. Essa situação nos remete ao fato de que, em tempos de acumulação flexível, onde ocorre um maior controle do trabalho e das técnicas de gestão por parte do capital (Antunes, 1999), sejam exercidas pressões mais fortes sobre uma força de trabalho enfraquecida em decorrência da reestruturação do capitalismo nas últimas décadas (Harvey, 1992) e, em particular, quanto à sua subjetividade.

Um outro relato informa que, ao sofrer acidente (queda), o trabalhador teve o joelho em choque com uma barra de pedra, o encarregado da obra o colocou para realizar atividade de reboco, ou seja, realiza sua tarefa em pé. Já que, na anterior, quando lidava com o contrapiso, precisava ficar agachado por muitas horas, posição esta que não consegue mais ficar, após o trauma no joelho direito. Contraditoriamente, este trabalhador informa que considera o seu local de trabalho organizado, mas denuncia a falta de luvas, botas e fardas para os trabalhadores, além do fato da empresa se recusar a pagar hora-extra.

Diante desse cenário, é possível dizer que a produção, de fato, não pode parar. Muda-se a atividade do trabalhador, mas, em favor da 
produtividade. E, a empresa não garante a resolutividade do agravo que afeta a saúde do trabalhador ocasionado no trabalho. Retrato explícito da precariedade do trabalho, no contexto do capitalismo contemporâneo, mesmo nos casos em que o trabalhador possui carteira assinada.

Quanto às doenças de origem músculo-esquelético entre, a principal causa, mencionada pelos trabalhadores, é o fato de (2) carregar excesso de peso, ressaltando que essa atividade pode perdurar por horas durante um dia de trabalho. Um dos trabalhadores relatou o seguinte: “(...) Os maiores riscos são decorrentes do trabalho braçal com excesso de peso". Em geral, os blocos ou pedras de concreto, as tábuas e compensados, só para citar alguns materiais, têm o peso superior ao que o corpo pode suportar. No âmbito da normatização da carga de peso a ser transportada pelo trabalhador, convive-se ainda com uma legislação favorável aos interesses da produção e do capital ${ }^{\text {xiii }}$.

Ainda sobre a tarefa de carregar excesso de peso e os efeitos nos membros superiores e inferiores e na coluna dos trabalhadores, uma declaração sintetiza a realidade enfrentada pelo conjunto de trabalhadores da construção civil: “(...) [a gente] trabalha carregando muito peso, (sic) concretagem, assentamento de tijolos e puxa concretagem, durante o dia todo".

A situação de precarização e, consequentemente, de penosidade no trabalho, em conseqüência de situações mencionadas nos relatos, agrava-se ainda mais em certos casos, como descrito a seguir: "[a trabalhadora] trabalhou com a tia prestando serviço de limpeza a fase final da construção por, aproximadamente, dezenove anos, sem carteira assinada. Relata ainda que transportava vários objetos pesados, sentia muitas dores nas costas (...)". Recentemente, esta trabalhadora foi diagnosticada com escoliose e artrose na coluna, em estágio avançado. Porém, ela considera, contraditoriamente, o seu local de trabalho organizado e sem muitos riscos, exceto pela atividade de carregar objetos 
pesados.

A (3) permanência prolongada de posições (em pé, sentado ou agachado) durante as extenuantes jornadas de trabalho que, no mínimo, são de 10 (dez) horas diárias, durante seis dias da semana, acrescida da realização de horas extras freqüentes, obriga o trabalhador da construção civil a lidar com os efeitos desta extenuante jornada diária de trabalho no seu próprio corpo. Dentre os relatos que apontam o desenvolvimento da experiência da dor, seja na coluna, seja nos membros (inferiores ou superiores), três deles merecem destaques, por resumirem o conteúdo dos demais relatos e por apresentarem os efeitos na vida social e os arranjos que os trabalhadores adotam, em certos casos, para lidar com a situação de adoecimento.

O fragmento do depoimento, a seguir, traduz de modo significativo a questão acima mencionada: “em agosto de $2009^{\text {xiv }}$, após um dia de trabalho 'enchendo a betoneira' ${ }^{\text {xv }}$, sentiu forte dor lombar". Desde este momento, ele "não consegue carregar a filha de um ano. Sente dificuldade para dormir, muda de posição sem sucesso (...)". Observa-se, assim, que não é só o corpo do trabalhador que é afetado. Além dos limites de movimentos de membros ou da coluna, afeta inevitavelmente a sua subjetividade, isto é, “(...) suas dimensões cognitivas, seu registro emocional, afetivo e moral (...)" (Linhart, 2011, p. 152).

O segundo caso, diz respeito a um trabalhador que informou que desde quando iniciou dor intensa nos joelhos, acerca de um ano, faz uso de medicamentos, mas a dor permanece. Diz que "não consegue trabalhar agachado e nem fletir o tronco (...) tem dificuldade para descer degraus”. Por isso, informou que “(...) não conseguiu exercer suas atividades devido exigirem esforço físico que ainda não consegue fazer”.

Por fim, um terceiro relata que sente dores na coluna e dormência nas mãos e pernas há cerca de dois anos. Diz também que ficou afastado inúmeras vezes e, quando isso ocorre, sente a diminuição das dores na coluna. Este trabalhador atua na construção civil desde os treze anos como 
ajudante de pedreiro e, atualmente, aos 51 anos, continua em atividade e trabalha como pedreiro.

O (4) contato com produtos químicos, como thinner, ácido pneumático, tinta, etc. pode desencadear diversos sintomas por quem manipula tais produtos, tais como: cefaléia, tontura, ardência nos olhos e mucosas, irritação e prurido na pele, náuseas, entre outros. O agravo mais freqüente, nesse caso, é o de dermatite ocupacional ${ }^{\mathrm{xvi}}$. O número de queixas relacionadas a este agravo tem aumentados nos últimos anos, porém ainda não tem recebido a devida atenção de pesquisadores ou mesmo dos serviços/ ações voltadas para a Saúde do Trabalhador no âmbito do Sistema Único de Saúde (SUS).

Um dos trabalhadores, por exemplo, afirma que sente dores nas mãos e pés e irritação na pele, desde o ano de 1999, quando já atuava como servente (auxiliar de pedreiro) em empresa da construção civil. Sua função principal, na atualidade, é de limpar os apartamentos novos, ou seja, ele "retira entulho e resto de materiais de construção com o uso de produtos químicos como thinner nas janelas, água sanitária para as manchas de parede, ácido pneumático para manchas de piso cerâmico e de revestimento (...)". Informa também que após “a aplicação de produtos químicos, retirava-se por trinta minutos por causa da fumaça de névoa. Ao retornar, jogava água (...) com a mangueira a jato, porém permanecia o cheiro de produtos químicos, por vezes causando: cefaléia, tontura, ardência dos olhos e mucosas, irritação e prurido na pele e náuseas ${ }^{\text {xvii, }}$.

O contato com produtos químicos sem as devidas proteções, por parte de equipamentos de proteção (EP's) ou mesmo a exposição por um tempo superior ao preconizado pela legislação vigente, expõe o trabalhador às situações de risco iminente. A respeito da disponibilidade, por parte das empresas, dos EP's, sejam eles individuais ou coletivos, é importante notar que algumas situações se impõem, de acordo com a maioria dos relatos: irregularidade na oferta, inadequação quanto à qualidade e ausência de 
equipamentos mais específicos para aqueles que desenvolvem atividades esporádicas.

O quadro exposto acima revela que os efeitos no processo saúdedoença entre os trabalhadores da construção civil devem ser explicados a partir da lógica da reprodução capitalista - com a necessidade de geração de mais-valor - e os seus efeitos sobre o trabalho, e não a partir da centralidade da doença ou do acidente. Nesse contexto, pode-se dizer que a "enorme intensificação dos ritmos, tempos e processos de trabalho" (Antunes, 2007, p. 04), em que o trabalhador é submetido, não é ditada por sua vontade individual. Ao contrário, ele realiza suas tarefas e funções no interior do espaço do trabalho de acordo com a prescrição da dinâmica da produção capitalista, mesmo que isso custe a convivência com a dor, às vezes durantes anos, limitações de movimentos dos membros ou, em muitos casos, a sua própria vida.

\section{(In) Conclusões}

Nos últimos decênios, cada vez mais, convive-se, com o modo fragmentado, multifacetado e heterogêneo do mundo do trabalho (Antunes, 2004, p. 15), nos seus diferentes campos. No âmbito da Indústria da Construção Civil (ICC), este fenômeno se revela a partir de múltiplas configurações, como o progressivo aumento da precarização das relações de trabalho combinado à inserção de modernas tecnologias de produto e equipamentos. A intensa rotatividade de mão-de-obra, enquanto recurso periódico por parte do capital na busca de mecanismo para a redução de salário do trabalhador, e o aumento da intensidade do trabalho, com a incorporação de metas de produção e o uso abusivo de horas-extras, ampliam-se e ganham contornos significativos, mesmo quanto se trata de relações formais de trabalho. 
A ampliação do trabalho terceirizado (por meio das empresas incorporadoras) e do trabalho informal, do diarista, do empreiteiro, do biscateiro, etc., expõe a incorporação de ritmos e intensidades do trabalho mais céleres e, muitas vezes, mais degradantes. Entretanto, esse processo se desenvolve na construção civil, conforme analisa Villela (2007), sob a ótica da racionalidade capitalista, onde os diferentes processos de trabalho se orientam, contraditoriamente, entre o paradigma da manufatura e o da grande indústria.

Considerando a complexidade que é o processo de organização da produção e do trabalho na construção civil, outro aspecto expressivo é a amálgama entre a emergência de técnicas inovadoras e tecnologias modernas e a permanência de condições precárias e métodos rudimentares de trabalho. Diante disso, as situações degradantes no trabalho tornam-se freqüentes, sendo o corpo do trabalhador o locus central onde é possível constatar os contornos da precarização do/ no trabalho, seja quando o trabalhador adoece ou sofre um acidente, seja quando perde a vida.

A composição do quadro de agravos que (permanecem) afetando a saúde do trabalhador e os acidentes e óbitos no trabalho coincidem, em muitos casos, com as situações pretéritas vivenciadas por este setor (Santana e Oliveira, 2004; Santana et al., 2005; Gomes e Costa, 1997). Entretanto, por conta dos novos contornos e traços da reorganização do processo de trabalho na construção civil, emergem novas formas de adoecimentos (em virtude da incorporação de novos produtos ou materiais) ou a freqüência de determinados tipos de acidentes, em decorrência do aumento vertiginoso da intensidade do trabalho através, por exemplo, do estabelecimento de metas de produção, da contratação temporária para serviços específicos (diaristas, biscateiros, etc.) e da incorporação de horas-extras excessivas.

Não se quer dizer que os trabalhadores da construção civil estejam vivenciando situações de precariedade somente nos tempos atuais. Ao se 
admitir tal discurso, corre-se o risco real de sublimar o histórico das condições do trabalhador urbano brasileiro ${ }^{\text {xviii }}$. Só para ilustrar, em pesquisa realizada sobre a construção de Brasília, em meados dos anos de 1950, o autor comenta sobre as condições e relações de trabalho do passado, mas que socialmente revelam-se atuais e pertinentes:

\begin{abstract}
Os mecanismos de exploração internas à construção civil obedecem, claro à lógica da extração de sobre trabalho no capitalismo. (...) As formas que estão vinculadas ao acréscimo de horas à jornada de oito horas são, basicamente, na construção civil, as horas extras e a virada (RIBEIRO, 2008, p. 160)
\end{abstract}

Quanto às situações identificadas pelos trabalhadores, como desencadeadores de seus adoecimentos/ acidentes, conforme os seus relatos, foram: a) as quedas (de altura, piso irregular, etc.); b) o transporte de carga com excesso de peso; c) a permanência prolongada de posições (em pé ou agachado); e, d) o contato com produtos químicos. Em relação às queixas descritas pelos trabalhadores, a situação de dor chama a atenção. Exceto um trabalhador, num universo de quarenta e quatro, não mencionou a convivência com a dor, como as que acometem algum membro (superior ou inferior) ou a coluna. Essa constatação indica, de certo modo, que a precarização do/no trabalho impõe à vida do trabalhador traços de penosidade, onde é exigido dele que dê continuidade à execução de suas funções no trabalho, mesmo que isso implique a coexistência com a dor.

Apesar de que hoje há um relativo avanço do processo de regulamentação da legislação pertinente ao tema da saúde e da segurança no trabalho $^{\text {xix }}$ da construção civil e da institucionalização da política nacional voltada para a saúde do trabalhador no âmbito do Sistema Único de Saúde (SUS), é inegável que essas políticas públicas pouco conseguiram penetrar 
nos espaços de trabalho da construção civil, especialmente quanto à relação entre as necessidades do capital e as condições de saúde e doença nas quais estão inseridos milhares de trabalhadores.

Assim, sem deixar de reconhecer os efeitos sociais nefastos decorrentes das medidas de desregulamentação do trabalho e da ampliação de situações de precarização do trabalho e emprego, torna-se crucial reconhecer também que houve um relativo avanço da implementação da política voltada para a saúde do trabalhador, seja no âmbito do Sistema Único de Saúde (SUS), seja na área da previdência social, que vem contribuindo para a identificação, sistematização e publicização dos casos de doença e acidentes no trabalho. Não obstante, nem sempre isso se dá concomitantemente com o avanço das ações de assistência à saúde do trabalhador, ou seja, na prevenção, promoção, tratamento e reabilitação voltada para o trabalhador.

No que diz respeito ao SUS, o desafio ainda se impõe - que é o de incorporar a categoria trabalho como central para a compreensão do processo saúde-doença e, por conseguinte, fortalecer as ações e serviços em saúde do trabalhador (Facchini et. al., 2005, p. 859). Esse processo, no entanto, não se dá sem o enfrentamento às bases históricas do mix público/ privado na assistência à saúde, como sugere Menicucci (2007).

Nesses novos tempos, uma das faces da sociedade capitalista na contemporaneidade pode se revelar a partir do seguinte prisma:

"hoje, passado o susto e eliminada a aparentemente a tendência antagonista internacional, ela pode revelar sua face real: para os subalternos, a possibilidade de acesso, real e efetivo, no mundo da política e do bem estar social é quase nula, reduzindo-os, abertamente, à pura sobrevivência" (DIAS, 2006, p. 43).

E, é nessa condição de luta pela sobrevivência que ainda está submerso um número expressivo de trabalhadores da construção civil, 
mesmo que isto exija pôr-se em risco permanente de sofrer acidentes fatais ou incapacitantes ou mesmo desenvolver doenças que afetem a sua saúde.

\section{NOTAS}

${ }^{i}$ Entendo o conceito de reestruturação produtiva na perspectiva definida por G. Alves (2000), quando afirma que o "capital não pode subsistir sem revolucionar, de modo constante, os meios de produção. A intensa e incansável pressão para revolucionar a produção tende a extrapolar, impondo transformações nas 'condições de produção' (ou 'relações produtivas'), 'e, com elas, em todas as condições e relações sociais'” (p.20, grifo nosso). Nesse sentido, o trabalho na construção civil não está imune a essas recorrentes mudanças inerentes à dinâmica do capital e de sua reprodução social.

ii É o caso, por exemplo, "das estruturas metálicas (que substituem as estruturas de concreto armado), dos painéis de gesso acartonado (que substituem as paredes de alvenaria) e da argamassa semi-pronta, adquirida em embalagens (que substitui a argamassa 'solada no canteiro')" (DIEESE, ANO, p. 06).

iii De acordo com a lei $\mathrm{n}^{\circ} 8080 / 90$, a chamada "lei do SUS", com destaque para o art. $6^{\circ}$.

iv Apesar da própria "lei do SUS", indicar diretrizes para as ações em saúde do trabalhador nas três esferas de gestão, desde meados dos anos 2000, o Ministério da Saúde vem buscando regulamentar a referida ação estratégica no âmbito do SUS, como, por exemplo, as portarias n $n^{\circ} 777 / 2004$ e a 2437/ 2005.

v Conf. AEAT/ MPS/ INSS, 2006 e o AEAT/ MPS/ INSS, 2010.

vi Segundo informações do Superintendente do órgão, o Sr. Alcino Vieira dos Santos, divulgadas pelo Jornal Diário do Amazonas, em 28/ Nov 2010.

vii As informações apresentadas sobre o MPT/ AM foram retiradas de publicação do Jornal Diário do Amazonas, em 30/ ago 2010.

viii De acordo com informações fornecidas pelo Sr. Edmundo Néri, chefe da seção de saúde do trabalhador do INSS/ AM, divulgadas pelo Jornal Diário do Amazonas, em 30/ ago 2010.

ix Só para lembrar, é importante citar as paralisações empreendidas por trabalhadores da construção civil, no início do ano de 2011 e neste momento (março de 2012). Destaque para os movimentos de trabalhadores que atuam nas obras das usinas hidrelétricas de Jirau (a maior obra em andamento no país, com 22 mil trabalhadores), Santo Antônio (16 mil) --ambas em Rondônia-e São Domingos (3.000), no Mato Grosso do Sul.

x É importante informar que os relatos desses trabalhadores foram selecionados a partir dos prontuários dos mesmos, particularmente dos formulários denominados "Anamnese Social" e "Ocupacional". Do universo de 44 trabalhadores, 34 (trinta e quatro) trabalhadores informaram terem sido encaminhados pelo Sindicato dos Trabalhadores da Construção Civil- 
SINTRACOMEC, e todos os trabalhadores atendidos no CEREST/ Manaus tinham vínculos formais de trabalho.

xi Segundo o DIEESE, “(...) o bom desempenho do setor [da construção civil] nos últimos anos não tem se refletido na mesma proporção na melhoria das condições de trabalho e no rendimento dos trabalhadores do setor". In: DIEESE. Estudo Setorial da Construção Civil. n. 51, mai/ 2010. São Paulo: 2010.

xii Como não há maiores detalhes da situação em que ocorreu tal acidente, não podemos inferir sobre as condições e situações de trabalho, como a ausência ou não de pontes, de escadas, etc., nos locais de trabalho, conforme preconiza a normatização vigente.

xiii Ver melhor Constituição Federal Brasileira, de 1988. Art. $5^{\circ}$.

xiv Considerando que o primeiro atendimento deste trabalhador no CEREST/ SEMSA foi em janeiro de 2010.

xv Só para ilustrar, as tarefas básicas de quem trabalha com a betoneira é a seguinte: carrega sacas de cimento, transporta carrinho de massa, enche areia na betoneira, de acordo com o tempo estipulado pelo mestre de obra. (G.S.A, 12).

xvi A dermatose ocupacional pode ser definida como "toda alteração das mucosas, pele e seus anexos que seja direta ou indiretamente causada, condicionada, mantida ou agravada por agentes presentes na atividade ocupacional ou no ambiente de trabalho". Conf. BRASIL. Ministério da Saúde. Dermatose Ocupacional - protocolo de complexidade diferenciada. Brasília: Editora do Ministério da Saúde, 2006.

xvii Este trabalhador, após inúmeros afastamentos, entrou "em acordo" com a empresa e pediu a conta. Ele afirmar que, "sem trabalhar, houve melhora da falta de ar, permanecendo dores nas costas, mãos e pés".

xviii Para Pochmann et. al. (2007), "O monopólio do escravo na realização de quase todas as ocupações (lavrador, fabricante de açúcar e aguardente, cozinheiro, sapateiro, carregador, entre outras tantas) tornou o trabalho no Brasil escravista estigmatizado como maldição e castigo, associado à marginalidade, inferioridade social e pobreza. Assim, a transição para o uso da mão-de-obra livre realizou-se dividida por categorias hierarquicamente distintas, com grandes levas de trabalhadores estrangeiros (brancos) considerados superiores aos brasileiros da época (escravos e mestiços), e estes últimos que continuaram submetidos à marginalização" (p. 21).

xix Sobre esse assunto é importante destacar a aprovação da Norma Regulamentadora n. 18. 


\section{Referências}

ALVES, Giovanni. O novo (e precário) mundo do trabalho - reestruturação produtiva e crise do sindicalismo. São Paulo: Boitempo, 2000.

. Dimensões da reestruturação produtiva - ensaios de sociologia do trabalho. São Paulo: Práxis, 2007.

ANTUNES, Ricardo. Adeus ao Trabalbo? Ensaio sobre as metamorfoses e a centralidade do mundo do trabalho. 6. ed. São Paulo: Ed. Cortez; Campinas, SP: Ed. UNICAMP, 1999.

Os Sentidos do Trabalho: ensaio sobre a afirmação e a negação do trabalho. 5. ed. São Paulo: Boitempo Editorial, 2001.

- A Dialética do Trabalho - escritos de Marx e Engels. São Paulo:

Expressão Popular, 2004.

- Anotações sobre o capitalismo recente e a reestruturação produtiva no Brasil. In: ANTUNES, R. e SILVA, $\mathrm{M}^{\mathrm{a}}$ A. Moraes (Orgs.). O avesso do trabalho. São Paulo: Expressão Popular, 2004, p. 13-27.

BOITO Jr., Armando. Política Neoliberal e Sindicalismo no Brasil. 2 ed. São Paulo: Xamã, 1999.

BRASIL, Ministério da Previdência Social e Assistência Social 2005. Anuário Estatístico de Acidente do Trabalho - AEAT - 2005. <acessado em 03/11/2009>.

. Ministério da Previdência Social e Assistência Social 2006.

Anuário Estatístico de Acidente do Trabalho - AEAT - 2006. < acessado em 23/11/2009>.

. Ministério da Previdência Social e Assistência Social 2007

Anuário Estatístico de Acidente do Trabalho - AEAT - 2007. <acessado em $23 / 11 / 2009>$.

. Ministério da Previdência Social e Assistência Social 2008.

Anuário Estatístico de Acidente do Trabalho - AEAT - 2008. <acessado em $23 / 11 / 2009>$. 
. Ministério da Previdência Social e Assistência Social 2009.

Anuário Estatístico de Acidente do Trabalbo - AEAT - 2009. <acessado em 05/04/2010>.

. Ministério da Previdência Social e Assistência Social 2010.

Anuário Estatístico de Acidente de Trabalho - AEAT-2010. <acessado em 03/02/2012>.

BRASIL, Ministério da Saúde 2004. Portaria Federal n 777/ GM, de 28 de abril de 2004.

Departamento Intersindical de Estatísticas e Estudos Sócio-econômicosDIEESE. Estudo Setorial da Construção Civil, n. 12. São Paulo: 2001.

Paulo: 2010 .

. Estudo Setorial da Construção Civil, n. 51, mai/ 2010. São

DIAS, Edmundo Fernandes. Política brasileira: embates de projetos hegemônicos.

São Paulo: Ed. Instituto José Luis e Rosa Sundermann, 2006.

FACCHINI, LA et. al. Sistema de Informações em Saúde do Trabalhador: desafios e perspectivas para o SUS. Vol. 10, No 04. Ciência \& Saúde Coletiva. Rio de Janeiro: ABRASCO, 2005.

GOMEZ, Carlos M. e LACAZ, F. A. de Castro. Saúde do Trabalhador: novasvelhas questões. In: Revista Ciência \& Saúde coletiva, V. 10, nº 04, Rio de Janeiro: ABRASCO, 2005.

- A construção do campo da saúde do trabalhador: percursos e dilemas. Caderno de Saúde Pública, Rio de Janeiro 13 (Supl. 2): 21-32, 1997.

HARVEY, David. A Condição Pós-Moderna: uma pesquisa sobre as origens da mudança cultural. Tradução de Adail Sobral e Maria Stela Gonçalves. $3^{a}$. ed. São Paulo: Ed. Loyola, 1993. 
LEITE, Márcia de P. Trabalho e Sociedade em transformação - mudanças produtivas e atores sociais. São Paulo: Fund. Perseu Abramo, 2003.

LOURENÇO, Edvania E. de S. e BERTANI, Iris F. Saúde do Trabalhador no SUS: desafios e perspectivas frente à precarização do trabalho. Revista Brasileira de Saúde Ocupacional, São Paulo. 32 (115): 121-134, 2007 <acessado em 15 de jan. de 2012>.

RIBEIRO, Gustavo Lins. O capital da esperança - a experiência dos trabalhadores na construção de Brasília. Brasília: Editora da UNB, 2008.

MARX, Karl. Manuscritos Econômico-filosóficos. 1 ed. São Paulo: Boitempo, 2004.

MENICUCCI, Telma Ma Gonçalves. Público e Privado na Política de Assistência à saúde no Brasil. Rio de Janeiro: FIOCRUZ, 2007.

POCHAMANN, Márcio (Org.). Trabalhadores urbanos: ocupação e queda na renda - Atlas da nova estratificação social no Brasil, Vol. 2. São Paulo: Cortez, 2011.

SANTANA V. S. et. al. Acidentes de trabalho no Brasil entre 1994 e 2004: uma revisão. In: Revista Ciência \& Ciência Coletiva, V. 10, N. 4, out/ dez 2005.

SANTANA V. S. e OLIVEIRA, R. P. Saúde e trabalho na construção civil em uma área urbana do Brasil. In: Caderno de Saúde Pública. Rio de Janeiro, 20 (3): 797-811, mai-jun, 2004.

VILLELA, Fábio Fernandes. Indústria da Construção Civil e Reestruturação Produtiva: Novas Tecnologias e Modos de Socialização Construindo o Intelecto Coletivo ("General Intellect"). Tese de Doutoramento, Campinas, Instituto de Ciências Humanas e Letras/ UNICAMP, 2007. 